Check for updates

Cite this: RSC Adv., 2017, 7, 29035

Received 31st March 2017

Accepted 28th May 2017

DOI: $10.1039 / \mathrm{c} 7 \mathrm{ra03723f}$

rsc.li/rsc-advances

\section{Mechanistic study on ligand-controlled copper- catalyzed regiodivergent silacarboxylation of allenes with carbon dioxide and silylborane $\uparrow$}

\begin{abstract}
Shu-Min Han, ${ }^{a}$ Xingdong Wang, ${ }^{b}$ Shenhua Miao, ${ }^{* a}$ Zhang-Yu Yu ${ }^{\text {ab }}$ and Tao Liu (D) *ab
Recently, Tsuji and co-workers reported a ligand controlled regiodivergent silacarboxylation of allenes with $\mathrm{CO}_{2}$ and a silylborane in the presence of a copper catalyst. Product $\mathrm{P}_{1}$ was generated in the rac-Me-DuPhos $\left(L_{A}\right)$ assisted system while product $P_{2}$ was obtained in the $P C y_{3}\left(L_{B}\right)$ assisted system. To account for the observed regioselectivity, density functional theory (DFT) calculations have been carried out in the present study. We calculated the detailed mechanisms and analyzed electronic and steric factors in the selectivity-determining states TS3A, TS9A, TS2B, and TS5B to gain insight into the origin of the observed regioselectivity. For the $L_{A}$-assisted system, the regioselectivity is predicted to be determined by the great steric effects of TS9A. The more stable geometry of TS3A causes $\mathrm{P}_{1}$ to be the major product. For the $L_{B}$-assisted system, electronic effects can account for the regioselectivity. The stronger attractive interaction in TS5B compared with that in TS2B leads to the generation of $\mathrm{P}_{2}$.
\end{abstract}

\section{Introduction}

As useful building blocks in organic synthesis, organosilanes can undergo a good deal of silicon-assisted transformations. ${ }^{1}$ In particular, silylcupration of $\mathrm{C}-\mathrm{C}$ multiple bonds (especially the allene derivatives) has become one of the most reliable and powerful procedures that forms both vinyl- and allyl-silanes. ${ }^{2}$ However, how to control the selectivity has become the serious problem since the addition reactions across unsaturated substrates often result in many regio- and stereo-isomers. ${ }^{2 g, 3}$ The first-row transition metals have often been used as catalysts to solve the problem, ${ }^{4}$ not only due to their considerably low price, but the differing electronic structures of $3 \mathrm{~d}$ transition metals provide promise for developing significant molecular structures and uncovering new organometallic reactivities at a fundamental level..$^{5}$ In addition, as a greenhouse gas providing serious harm to the environment, carbon dioxide $\left(\mathrm{CO}_{2}\right)$ capture, utilization, and conversion have become hot topics in research. ${ }^{6}$

Recently, Tsuji and co-workers reported a ligand controlled regiodivergent silacarboxylation of allenes with $\mathrm{CO}_{2}$ and a silylborane in the presence of a copper catalyst (Scheme 1). ${ }^{7}$ As shown in Scheme 1, the ratio of two different products $\mathbf{P}_{\mathbf{1}}$ and $\mathbf{P}_{\mathbf{2}}$ can be highly controlled by the proper choice of ligand. The major product is $\mathbf{P}_{\mathbf{1}}$ in reaction condition $\mathrm{A}$ (when $\mathrm{Cu}(\mathrm{OAc})$ is

${ }^{a}$ School of Chemistry and Chemical Engineering, Qufu Normal University, Qufu 273165, Shandong, China. E-mail: liutao_2005@126.com

${ }^{b}$ Department of Chemistry and Chemical Engineering, Jining University, Qufu 273155, Shandong, China

$\dagger$ Electronic supplementary information (ESI) available. See DOI: $10.1039 / \mathrm{c} 7 \mathrm{ra} 03723 \mathrm{f}$ used as the catalyst precursor, hexan as the solvent, and the racMe-DuPhos ( $\left.\mathbf{L}_{\mathbf{A}}\right)$ as the ligand). In contrast, the major product is changed to $\mathbf{P}_{2}$ when a mixture of $\mathrm{CuCl} / \mathrm{NaOAc}$ was used as the catalyst precursor, THF as the solvent, and $\mathrm{PCy}_{3}\left(\mathbf{L}_{\mathbf{B}}\right)$ as the ligand (reaction condition B, Scheme 1).

To account for the observed regioselectivity of this reaction, a plausible mechanism has been proposed by Tsuji et al. ${ }^{7} \mathrm{As}$ shown in Scheme 2, a Cu catalyst precursor first reacts with one reactant $\mathbf{R} 1$ to form a silylcopper complex $\mathbf{1}$. Next, another reactant $\mathbf{R} 2$ coordinates to the $\mathrm{Cu}$ center of $\mathbf{1}$ via the terminal double bond and generates two isomers $\mathbf{2}$ and $\mathbf{5}$ according to the orientation of the unsymmetrical allene R2, which is followed by the subsequent alkene insertion to form the allylcopper complex 3 and vinylcopper complex 6, respectively. With $\mathrm{CO}_{2}$ inserting at the $\gamma$-position of 3, copper carboxylate complex 4 is afforded. Finally, through the $\sigma$-bond metathesis between 4 and R1, boron carboxylate $\mathbf{P}_{\mathbf{0 - 1}}$ is produced, accompanied with the 1 regenerating. Through the conversion with $\mathrm{H}_{3} \mathrm{O}^{+}$and $\mathrm{Me}_{3} \mathrm{SiCHN}_{2}$ further, $\mathbf{P}_{\mathbf{0}-\mathbf{1}}$ could afford the final product $\mathbf{P}_{\mathbf{1}}$. In contrast, the insertion of $\mathrm{CO}_{2}$ into 6 generates intermediate 7 , followed by the $\sigma$-bond metathesis with $\mathbf{R} 1$ to provide boron carboxylate $\mathbf{P}_{\mathbf{0 - 2}}$ and regenerate $\mathbf{1}$. Finally, final product $\mathbf{P}_{\mathbf{2}}$ could be obtained through the further conversion of $\mathbf{P}_{\mathbf{0}-2}$ with $\mathrm{H}_{3} \mathrm{O}^{+}$ and $\mathrm{Me}_{3} \mathrm{SiCHN}_{2}$.

Although a plausible mechanistic pathway has been proposed by Tsuji group, some key issues still need to be further discussed. (1) What is the detailed reaction mechanism? (2) How is the origin of this high ligand-controlled regioselectivity? Here we would like to report our detailed density functional theory (DFT) calculations on the reaction mechanisms in order to gain insight into the interesting experimental observations 


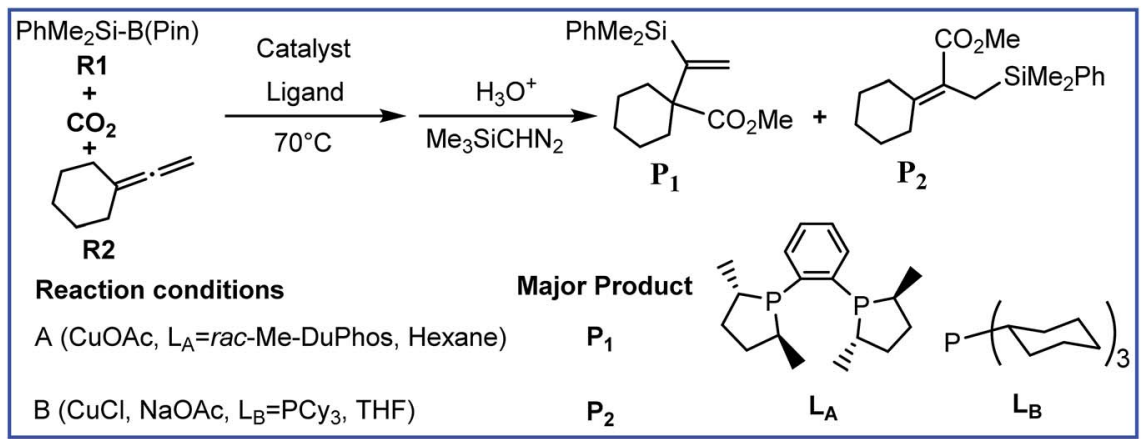

Scheme $1 \mathrm{Cu}$-catalyzed silacarboxylation of allenes with $\mathrm{CO}_{2}$ and silylborane reported by Tsuji group.

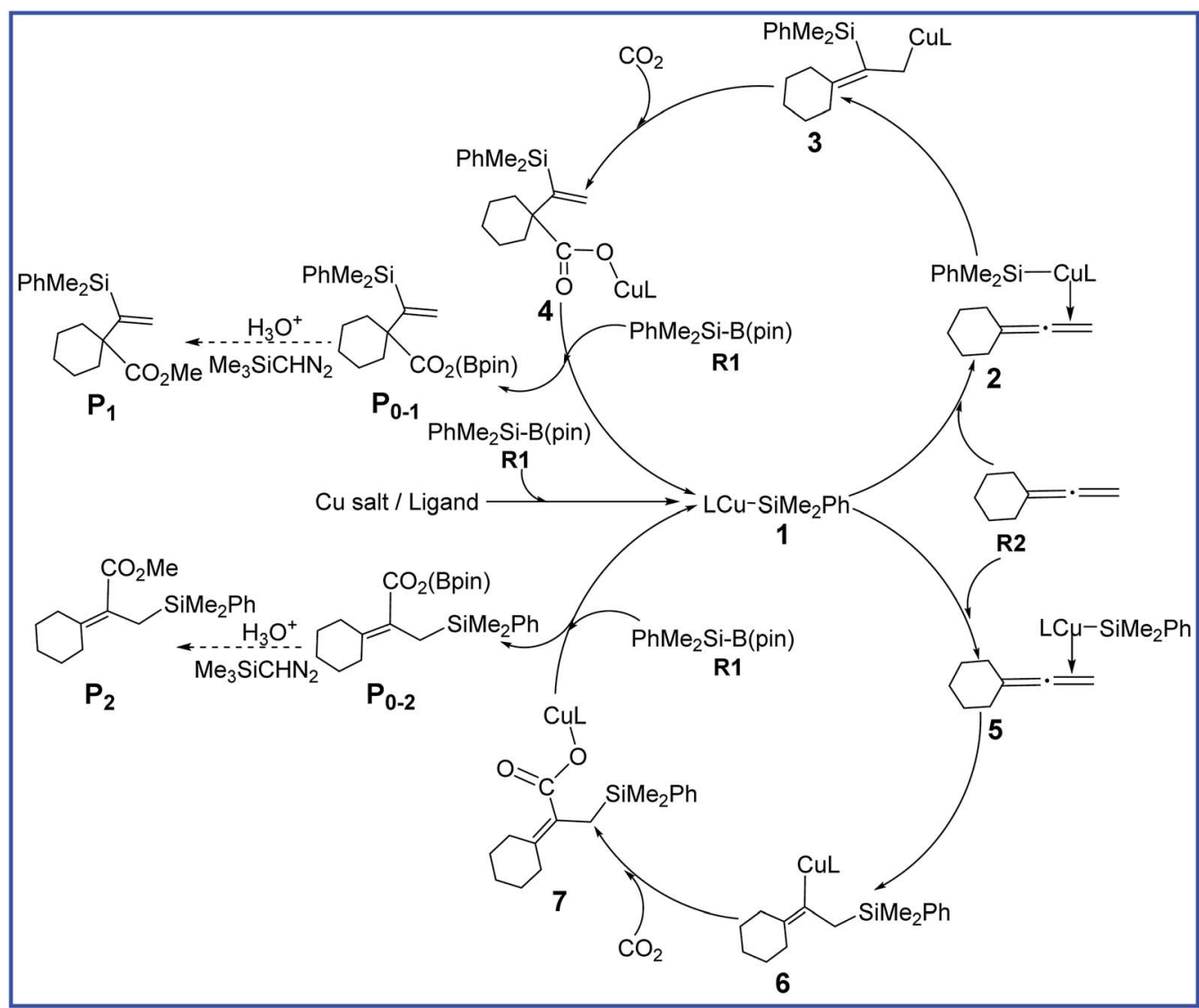

Scheme 2 Mechanisms of $\mathrm{Cu}$-catalyzed silacarboxylation of allenes with $\mathrm{CO}_{2}$ and silylborane proposed by Tsuji group.

and distinct selectivity. We expect this work would help understand the detailed mechanisms and design new related reactions.

\section{Computational details}

In our calculations, the geometries of all intermediates and transition states were optimized at the B3LYP ${ }^{8}$ level of DFT in gas phase. A mixed basis set of $6-311+G(d)$ for $\mathrm{Cu}$ and $6-31 \mathrm{G}(\mathrm{d}, \mathrm{p})$ for other atoms (BSI) was used, which has been proved to be appropriate for the copper-catalyzed reactions. ${ }^{9}$ Frequency analysis were carried out to ensure all stationary points as minima (zero imaginary frequencies) or transition states (one imaginary frequency) at the B3LYP/BSI level. When necessary, intrinsic reaction coordinates (IRC) ${ }^{\mathbf{1 0}}$ calculations were applied for transition state to confirm it actually connecting the corresponding two minima. To consider solvent effects, we performed single-point energy calculations for all the gas-phase optimized structures with $\mathrm{SMD}^{\mathbf{1 1}}$ solvent model at the M06 (ref. 12)/BSII (6-311+G(d) for $\mathrm{Cu}$ and $6-311++\mathrm{G}(\mathrm{d}, \mathrm{p})$ for other atoms) level. Natural bond orbital (NBO) ${ }^{13}$ charges were calculated for selected structures at the M06/BSII level. Free energies (kcal $\mathrm{mol}^{-1}$ ) obtained at the M06/BSII//B3LYP/BSI level were used in 
the following discussion. All the calculations were carried out with the GAUSSIAN 09 packages. ${ }^{14}$

\section{Results and discussion}

In this work, we first investigate the $\mathbf{C u} / \mathbf{L}_{\mathbf{A}}$-catalyzed mechanisms leading to $\mathbf{P}_{\mathbf{0 - 1}}$ and $\mathbf{P}_{\mathbf{0 - 2}}$, respectively (reaction A). Then we study the reaction mechanisms catalyzed by $\mathbf{C u} / \mathbf{L}_{\mathbf{B}}$ (reaction B) to probe the regioselectivity observed experimentally.

\section{1 $\mathrm{Cu} / \mathrm{L}_{\mathrm{A}}$-catalyzed reaction mechanisms}

The free energy diagrams for the reaction to lead to product $\mathbf{P}_{\mathbf{0}-\mathbf{1}}$ catalyzed by $\mathbf{C u} / \mathbf{L}_{\mathbf{A}}$ are calculated and shown in Fig. 1 . Firstly, the precatalyst CuOAc (1A) coordinates with the ligand $\mathbf{L}_{\mathbf{A}}$ to form the active catalyst $2 \mathrm{~A}$ by releasing the free energy of $57.0 \mathrm{kcal} \mathrm{mol}^{-1}$. Subsequently, the transmetalation of $\mathbf{2 A}$ with $\mathbf{R} 1$ occurs to generate a three-coordinate $\mathrm{Cu}(\mathrm{I})$ intermediate $\mathbf{3 A}$ and dissociate the complex $\mathrm{B}(\mathrm{pin})-\mathrm{OAc}$, through a concerted four-centered transition state TS1A related to $\sigma$-bond metathesis. This step is thermodynamically and kinetically feasible, with free energy decreasing of $6.8 \mathrm{kcal} \mathrm{mol}^{-1}$ as well as an attainable activation free energy ( $8.6 \mathrm{kcal} \mathrm{mol}^{-1}$ ). The terminal double bond of reactant $\mathbf{R} 2$ then coordinates to the $\mathrm{Cu}$ center of silylcopper intermediate $\mathbf{3 A}$ along with the dissociation of one arm of $\mathbf{L}_{\mathbf{A}}{ }^{15-17}$ via the transition state TS2A and generates intermediate $4 \mathrm{~A}$ with a barrier of $8.6 \mathrm{kcal}$ $\mathrm{mol}^{-1}$. The subsequent alkene insertion step requires a low activation energy barrier of $7.5 \mathrm{kcal} \mathrm{mol}^{-1}$ via transition state TS3A to form the allylcopper intermediate $\mathbf{5 A}$. The energy barrier is $\mathbf{1 4 . 4}$ $\mathrm{kcal} \mathrm{mol}^{-1}$ for the migratory insertion step (3A $\rightarrow$ TS3A). In the next step, $\mathrm{CO}_{2}$ inserts at the $\gamma$-position of $\mathbf{5 A}$ to a provide copper carboxylate complex 7A via a six-membered-ring transition state TS4A with the activation energy barrier of $12.2 \mathrm{kcal} \mathrm{mol}^{-1}$. The stepwise pathway for the $\mathrm{CO}_{2}$ insertion step $\left(\mathrm{CO}_{2}\right.$ first inserting into the $\mathrm{C}-\mathrm{Cu}$ bond of $\mathbf{5 A}$ to give carboxylate intermediate $\mathbf{6 A}$, which then undergoing a [1,3]-sigmatropic rearrangement to afford 7A) was also considered (see the red line in Fig. 1), but the calculated results indicates that such a proposal is inaccessible due to the forbidden high barrier $\left(87.8 \mathrm{kcal} \mathrm{mol}^{-1}\right)$. Finally, 7A combines with $\mathbf{R} \mathbf{1}$ to form intermediate $\mathbf{8 A}$, which then produces boron carboxylate $\mathbf{P}_{\mathbf{0 - 1}}$ and regenerates 3A via a $\sigma$-bond metathesis transition state TS7A with an attainable free energy barrier 13.3 kcal mol ${ }^{-1}$. Through the conversion with $\mathrm{H}_{3} \mathrm{O}^{+}$and $\mathrm{Me}_{3} \mathrm{SiCHN}_{2}$ further, $\mathbf{P}_{\mathbf{0}-\mathbf{1}}$ could afford the final product $\mathbf{P}_{\mathbf{1}}$. As shown in Fig. 1,

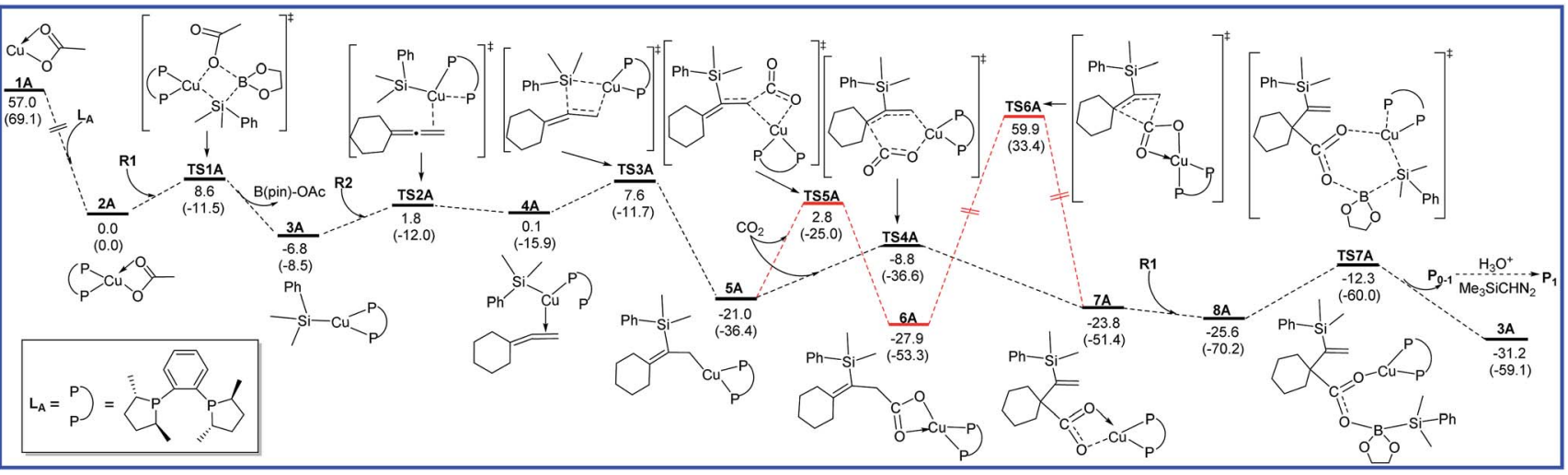

Fig. 1 Free energy diagrams to lead to $\mathrm{P}_{0-1}$ catalyzed by $\mathrm{Cu} / \mathrm{L}_{\mathrm{A}}$. The relative free energies and relative enthalpic energies (in parentheses) are given in $\mathrm{kcal} \mathrm{mol}^{-1}$.

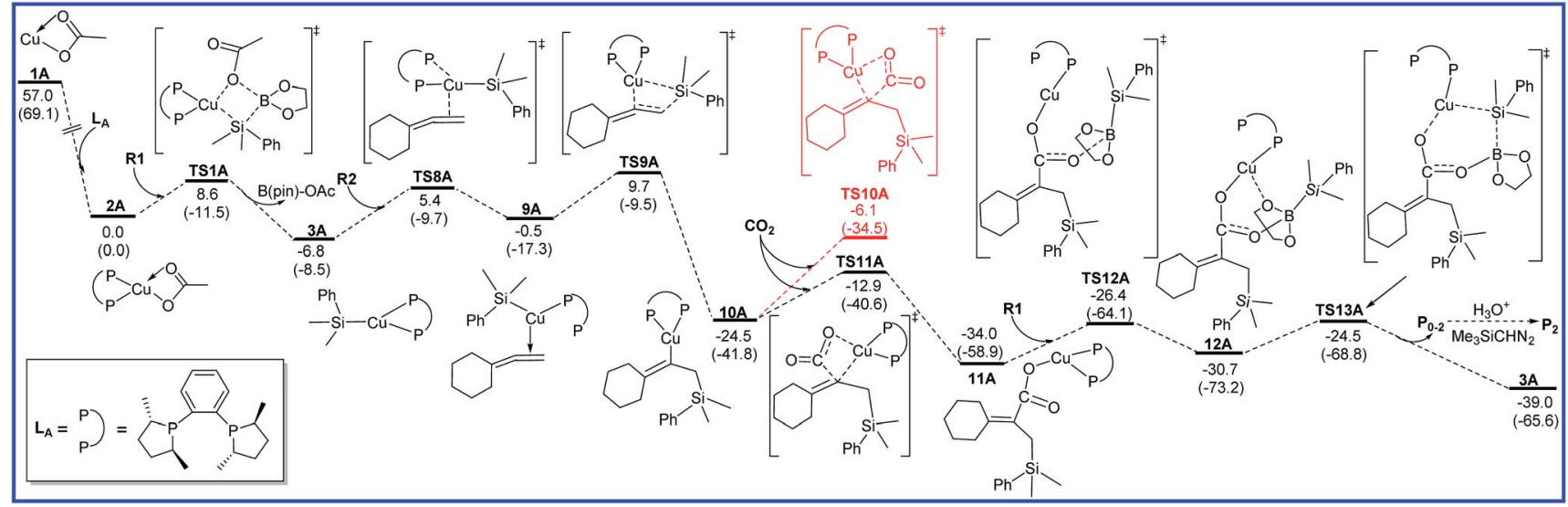

Fig. 2 Free energy diagrams to lead to $\mathrm{P}_{0-2}$ catalyzed by $\mathrm{Cu} / \mathrm{L}_{\mathrm{A}}$. The relative free energies and relative enthalpic energies (in parentheses) are given in $\mathrm{kcal} \mathrm{mol}^{-1}$. 


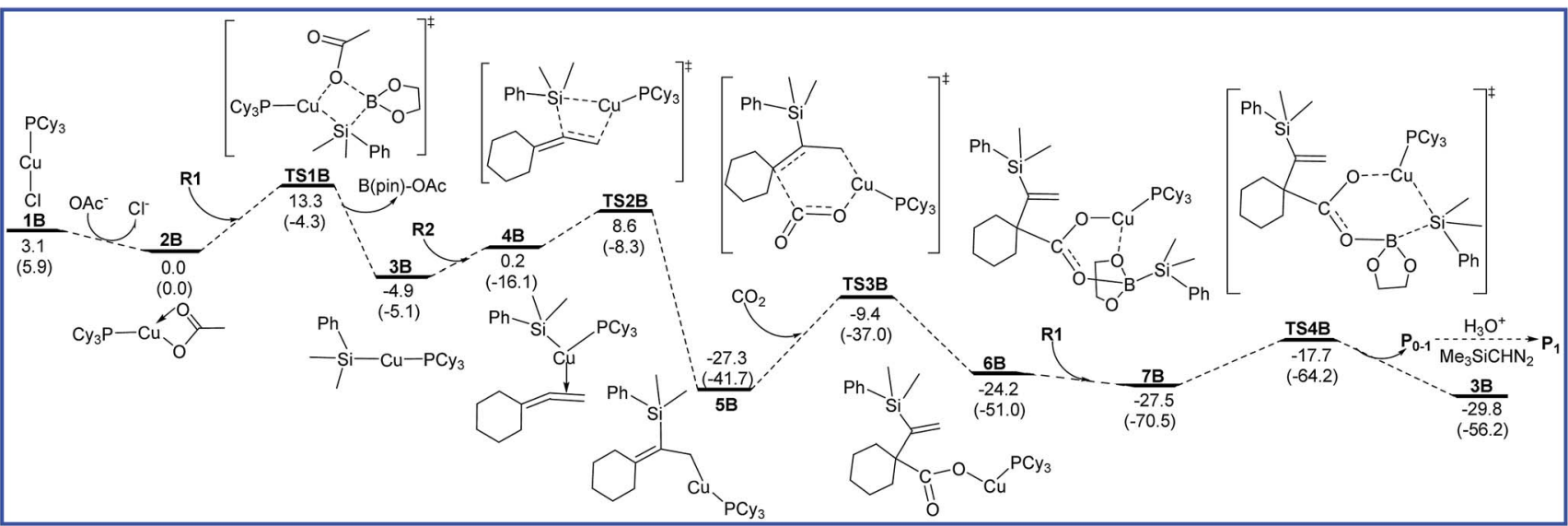

Fig. 3 Free energy diagrams to lead to $\mathrm{P}_{0_{-1}}$ catalyzed by $\mathrm{Cu} / \mathrm{L}_{\mathrm{B}}$. The relative free energies and relative enthalpic energies (in parentheses) are given in $\mathrm{kcal} \mathrm{mol}^{-1}$.

the rate-determining step in reaction $\mathrm{A}$ to produce $\mathbf{P}_{\mathbf{0}-\mathbf{1}}$ is the alkene migratory insertion step $(\mathbf{3 A} \rightarrow \mathbf{T S 3 A})$ and the overall activation barrier is $14.4 \mathrm{kcal} \mathrm{mol}^{-1}$.

As shown in Fig. 2, R2 can also coordinate with $\mathbf{3 A}$ via another conformation to produce intermediate $\mathbf{9 A}$ with a barrier of $12.2 \mathrm{kcal} \mathrm{mol}^{-1}$ (TS8A). An intramolecular migratory insertion then occurs to form the vinylcopper intermediate $10 \mathrm{~A}$ through the transition state TS9A, which requires the activation energy barrier of $10.2 \mathrm{kcal} \mathrm{mol}^{-1}$. In the following step, $\mathrm{CO}_{2}$ inserts into the $\mathrm{C}-\mathrm{Cu}$ bond of $\mathbf{1 0 A}$ to afford a copper carboxylate intermediate 11A through a four-membered-ring transition state TS11A with a free energy barrier of $11.6 \mathrm{kcal} \mathrm{mol}^{-1}$. Herein, another $\mathrm{CO}_{2}$ insertion transition state TS10A was excluded due to the higher free energy compared with TS11A (-6.1 vs. -12.9 kcal $\mathrm{mol}^{-1}$ ). Then, 11A binds up with $\mathbf{R} 1$ to form intermediate 12A, followed by the $\sigma$-bond metathesis (TS13A) to afford boron carboxylate $\mathbf{P}_{\mathbf{0 - 2}}$ and regenerate $\mathbf{3 A}$ with an attainable free energy barrier $9.5 \mathrm{kcal} \mathrm{mol}^{-1}$. Finally, final product $\mathbf{P}_{2}$ could be obtained through the further conversion of $\mathbf{P}_{\mathbf{0}-2}$ with $\mathrm{H}_{3} \mathrm{O}^{+}$and $\mathrm{Me}_{3} \mathrm{SiCHN}_{2}$. It can be found from Fig. 2 that the alkene migratory insertion process $(3 \mathbf{A} \rightarrow$ TS9A $)$ is also the ratedetermining step with the overall activation barrier of 16.5 kcal $\mathrm{mol}^{-1}$ in reaction A leading to product $\mathbf{P}_{\mathbf{0 - 2}}$.

Taking the full process shown in Fig. 1 and 2 into account, the alkene migratory insertion step is the regioselectivity-determining step, and the competition between TS3A and TS9A determines the regioselectivity $\left(\mathbf{P}_{\mathbf{0 - 1}}\right.$ or $\left.\mathbf{P}_{\mathbf{0 - 2}}\right)$. The calculated free energy difference (2.1 kcal $\mathrm{mol}^{-1}$ ) between TS3A and TS9A is reasonable agreement with the experimental major product $\mathbf{P}_{\mathbf{1}}$.

\section{2 $\mathrm{Cu} / \mathrm{L}_{\mathrm{B}}$-catalyzed reaction mechanism}

The free energy diagrams for the reaction leading to $\mathbf{P}_{\mathbf{0}-\mathbf{1}}$ catalyzed by $\mathbf{C u} / \mathbf{L}_{\mathbf{B}}$ are shown in Fig. 3. At the entrance of the reaction, precatalyst $\mathrm{PCy}_{3} \mathrm{CuCl}$ (1B) transforms into the active catalyst $\mathrm{PCy}_{3} \mathrm{CuOAc}$ (2B) via the ligand substitution with the additive NaOAc. This process is exoergic by $3.1 \mathrm{kcal} \mathrm{mol}^{-1}$. 2B sequentially undergoes $\sigma$-bond metathesis with $\mathbf{R} 1$ to give the intermediate $3 \mathbf{B}$ with a barrier of $13.3 \mathrm{kcal} \mathrm{mol}^{-1}$. The transmetalation pathway of $\mathbf{1 B}$ with $\mathbf{R} \mathbf{1}$ was also considered, but the calculated high barrier rules out the possibility (see Fig. S1 in

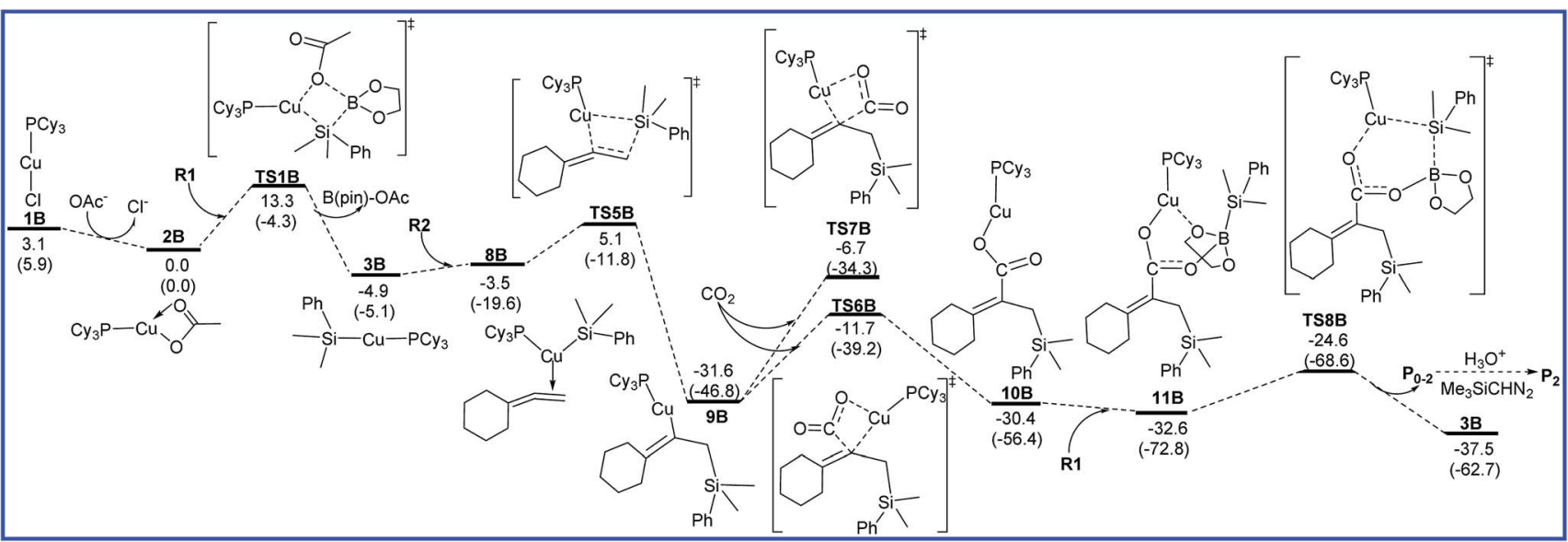

Fig. 4 Free energy diagrams to lead to $\mathrm{P}_{0-2}$ catalyzed by $\mathrm{Cu} / \mathrm{L}_{\mathrm{B}}$. The relative free energies and relative enthalpic energies (in parentheses) are given in $\mathrm{kcal} \mathrm{mol}^{-1}$. 
Table 1 Regioselectivity-determining and rate-determining steps in reactions $A$ and $B$, along with related activation energies (kcal mol ${ }^{-1}$ )

\begin{tabular}{|c|c|c|c|c|c|c|c|}
\hline \multirow{3}{*}{$\frac{\text { Reactions }}{\text { Reaction A }\left(\mathbf{C u} / \mathbf{L}_{\mathbf{A}}\right)}$} & \multirow{3}{*}{$\begin{array}{l}\text { Major product } \\
\mathbf{P}_{\mathbf{1}}\end{array}$} & \multicolumn{3}{|c|}{ Regioselectivity-determining step ${ }^{a}\left(\Delta G_{1}^{\ddagger}\right)$} & \multicolumn{3}{|c|}{ Rate-determining $\operatorname{step}^{b}\left(\Delta G_{2}^{\ddagger}\right)$} \\
\hline & & Alkene insertion & 3A $\rightarrow$ TS3A & $(14.4)$ & Alkene insertion & $\mathbf{3 A} \rightarrow \mathrm{TS} 3 \mathrm{~A}$ & $(14$. \\
\hline & & & 3A $\rightarrow$ TS9A & $(16.5)$ & & $3 A \rightarrow$ TS9A & $(16.5)$ \\
\hline
\end{tabular}

${ }^{a} \Delta G_{1}^{\ddagger}$, Gibbs free activation energy of rate-determining step. ${ }^{b} \Delta G_{2}^{\ddagger}$, Gibbs free activation energy of rate-determining step.

$\mathrm{ESI} \dagger$ ). Then, $\mathbf{R} 2$ inserts into the $\mathrm{Cu}-\mathrm{Si}$ bond via transition state TS2B to form a allylcopper intermediate 5B. The energy barrier of insertion process is $13.5 \mathrm{kcal} \mathrm{mol}{ }^{-1}$. The following $\mathrm{CO}_{2}$ insertion step requires the energy barrier of $17.9 \mathrm{kcal} \mathrm{mol}^{-1}$ to generate a copper carboxylate intermediate 6B via a sixmembered-ring transition state TS3B. Finally, $\sigma$-bond metathesis of $\mathbf{6 B}$ with $\mathbf{R} \mathbf{1}$ occurs to afford boron carboxylate $\mathbf{P}_{\mathbf{0 - 1}}$ and regenerate $3 \mathbf{B}$ with a free energy barrier $9.8 \mathrm{kcal} \mathrm{mol}^{-1}$. As shown in Fig. 3, the rate-determining step for the reaction leading to $\mathbf{P}_{\mathbf{0 - 1}}$ catalyzed by $\mathbf{C u} / \mathbf{L}_{\mathbf{B}}$ is $\mathrm{CO}_{2}$ insertion (5B $\rightarrow$ TS3B), and the overall energy barrier is $17.9 \mathrm{kcal} \mathrm{mol}^{-1}$.

The free energy diagrams for the reaction leading to $\mathbf{P}_{\mathbf{0 - 2}}$ catalyzed by $\mathbf{C u} / \mathbf{L}_{\mathbf{B}}$ are shown in Fig. 4 . From intermediate $3 \mathbf{B}$, the regioselectivity occurs. $\mathbf{R} 2$ inserts into the $\mathrm{Cu}-\mathrm{Si}$ bond of $\mathbf{3 B}$ towards another orientation via the transition state TS5B to form the vinylcopper intermediate $\mathbf{9 B}$ with an energy barrier of $10.0 \mathrm{kcal} \mathrm{mol}{ }^{-1}$. Then, $\mathrm{CO}_{2}$ inserts into the $\mathrm{C}-\mathrm{Cu}$ bond of $9 \mathbf{B}$ through a four-membered-ring transition state TS6B to form a copper carboxylate intermediate $\mathbf{1 0 B}$ with a free energy barrier of $19.9 \mathrm{kcal} \mathrm{mol}{ }^{-1}$. Another transition state TS7B for the $\mathbf{C O}_{2}$ insertion step was also calculated, but the higher relative free energy ( $6.1 \mathrm{kcal} \mathrm{mol}^{-1}$ ) indicates that this pathway is infeasible. Finally, 10B binds up with $\mathbf{R 1}$ to generate intermediate 11B, which is followed by the $\sigma$-bond metathesis (TS8B) to afford boron carboxylate $\mathbf{P}_{\mathbf{0 - 2}}$ and regenerate $3 \mathbf{B}$ with an attainable free energy barrier $8.0 \mathrm{kcal} \mathrm{mol}^{-1}$. As shown in Fig. 4, for the reaction leading to $\mathbf{P}_{\mathbf{0}-\mathbf{2}}$ catalyzed by $\mathbf{C u} / \mathbf{L}_{\mathbf{B}}$, the $\mathrm{CO}_{2}$ insertion process is found to be the rate-determining step with the overall activation barrier of $19.9 \mathrm{kcal} \mathrm{mol}^{-1}(\mathbf{9 B} \rightarrow$ TS6B).

As shown in Fig. 3 and 4 , the regioselectivity-determining steps to lead to $\mathbf{P}_{\mathbf{0 - 1}}$ and $\mathbf{P}_{\mathbf{0}-\mathbf{2}}$ catalyzed by $\mathbf{C u} / \mathbf{L}_{\mathbf{B}}$ are $3 \mathbf{B} \rightarrow$ TS2B (13.5 kcal mol ${ }^{-1}$ ) and 3B $\rightarrow$ TS5B (10.0 kcal mol $\mathrm{k}^{-1}$ ), respectively. The relative free energy difference $\left(3.5 \mathrm{kcal} \mathrm{mol}^{-1}\right)$ between TS2B and TS5B is reasonable agreement with the experimental major product $\mathbf{P}_{\mathbf{2}}$.

Other possible pathways were also considered. For example, in the transmetalation process of $\mathbf{1 B}$ and $\mathbf{R} \mathbf{1}$, the pathway that $\mathrm{PCy}_{3} \mathrm{Cu}$ moiety attacking toward $\mathrm{B}$ (pin) moiety, accompanied with the $\mathbf{R} 1$ moiety attacking toward $\mathrm{Cl}$ moiety was also considered, but the calculated results indicated that such a proposal is inaccessible (see Fig. S2 in $\mathrm{ESI} \dagger$ ). The inaccessible pathways that $\mathrm{CO}_{2}$ insertion prior to the alkene insertion step were also calculated (see Fig. S3 in ESI $\dagger$ ). The impact of additive NaOAc on the regioselectivity was also calculated and ruled out (see Fig. S4 in ESI $\dagger$ ).

In order to give a clear picture, the mechanistic scenarios for reactions $\mathrm{A}$ and $\mathrm{B}$ are summarized in Table 1. For reactions $\mathrm{A}$ and $\mathrm{B}$, the regioselectivity-determining and rate-determining steps together with activation energy barriers are presented. It can be seen from the table that the regioselectivity-determining step is the reaction of $\mathbf{3 A}(\mathbf{3 B})$ and $\mathbf{R 2}$ process, which is the divergence of $\mathbf{P}_{\mathbf{0 - 1}}$ and $\mathbf{P}_{\mathbf{0}-2}$. In addition, we can see all the reverse reactions of $\mathbf{3 A}(\mathbf{3 B})$ and $\mathbf{R} 2$ are unachievable kinetically with too high activation energies from the preceding energy diagrams. Consequently, it is predictive that reactions of $\mathbf{3 A}(\mathbf{3 B})$ and $\mathbf{R} \mathbf{2}$ are irreversible and thus this divergent step determines the major product $\left(\mathbf{P}_{\mathbf{1}}\right.$ or $\left.\mathbf{P}_{\mathbf{2}}\right)$. In other words, the major product is determined by the relative stability of the two divergent transition states from reaction of $\mathbf{3 A}(\mathbf{3 B})$ and $\mathbf{R} 2$.

For $\mathbf{C u} / \mathbf{L}_{\mathbf{A}}$-catalyzed reaction $\mathrm{A}$, generation of $\mathbf{P}_{\mathbf{1}}$ is calculated to be kinetically more favored than that of $\mathbf{P}_{2}$. The activation energy barrier difference between the two reactions is $2.1 \mathrm{kcal}$ $\mathrm{mol}^{-1}$ (TS3A vs. TS9A). The rate-determining steps are same to the regioselectivity-determining steps which predicted to be the alkene insertion for the two reactions. For $\mathbf{C u} / \mathbf{L}_{\mathbf{B}}$ reaction $\mathrm{B}, \mathbf{P}_{\mathbf{2}}$ becomes the major product, and the activation energy difference between the two reactions of $\mathbf{3 B}+\mathbf{R} 2$ is enlarged to $3.5 \mathrm{kcal}$



Fig. 5 Optimized structures for the transition states TS3A, TS9A, TS2B, and TS5B. Some important bond distances are given in $\AA$. The hydrogen atoms not participating in the reaction have been omitted for clarity. The values in parentheses are the related NBO charges (in e). 
$\mathrm{mol}^{-1}$. The rate-determining step is $\mathrm{CO}_{2}$ insertion process for the two reactions.

\subsection{Origin of the regioselectivity}

To gain insight into the origin of the observed regioselectivity, we checked both steric and electronic effects in the selectivitydetermining transition states TS3A, TS9A, TS2B, and TS5B. The important bond distances and NBO charges for the four transitions states are shown in the Fig. 5.

For $\mathbf{C u} / \mathbf{L}_{\mathbf{A}}$-catalyzed reaction $\mathrm{A}$, the steric effects are the major factors to account for the regioselectivity. As shown in Fig. 5, the $\mathrm{H} 1 \cdots \mathrm{H} 2$ and $\mathrm{H} 3 \cdots \mathrm{H} 4$ distances in TS9A are 2.13 and $2.15 \AA$, respectively, which are less than the sums of the van der Waals radii of hydrogen $(1.20 \AA)$. Thus, the great steric effects destabilize TS9A and rule out the possibility to lead to $\mathbf{P}_{\mathbf{2}}$ product in this reaction. In contrast, there are no obvious electronic effects difference in $\mathbf{C u} / \mathbf{L}_{\mathbf{A}}$-catalyzed reaction (TS3A and TS9A).

For $\mathbf{C u} / \mathbf{L}_{\mathbf{B}}$-catalyzed reaction $\mathrm{B}$, there are no obvious steric bias both in TS2B and TS5B. Compared the corresponding NBO charges in Fig. 5, it can be found that the $\mathrm{Cu}$ atom become more negatively charged when the attached ligand $\mathbf{L}_{\mathbf{A}}$ is replaced by $\mathbf{L}_{\mathbf{B}}$. As shown in Fig. 5, more negative $\mathrm{C} 2$ atom combines with the less positive $\mathrm{Cu}$ atom in TS2B, while combines with the more positive atom Si in TS5B. Obviously, the stronger attractive interaction caused by electronic factors in TS5B leads to the major product $\mathbf{P}_{2}$.

\section{Conclusions}

We have presented a detailed and plausible mechanism for the copper-catalyzed ligand controlled regiodivergent silacarboxylation of allenes with $\mathrm{CO}_{2}$ and silylborane by using DFT calculations. Two reactions are included in this study, reactions A (CuOAc as the catalyst and product $\mathbf{P}_{\mathbf{1}}$ is favored with the bidentate $\mathbf{L}_{\mathbf{A}}$ ligand), and $\mathrm{B}(\mathrm{CuCl} / \mathrm{NaOAc}$ as the catalyst and product $\mathbf{P}_{\mathbf{2}}$ is favored with the monodentate $\mathbf{L}_{\mathbf{B}}$ ligand). The ratedetermining steps for the reactions to form products $\mathbf{P}_{\mathbf{1}}$ and $\mathbf{P}_{\mathbf{2}}$ catalyzed by $\mathbf{C u} / \mathbf{L}_{\mathbf{A}}$ both are the alkene insertion step, while ratedetermining steps for the reactions catalyzed by $\mathbf{C u} / \mathbf{L}_{\mathbf{B}}$ both are the $\mathrm{CO}_{2}$ insertion step.

The origin of the experimentally observed selectivity on different products has been analyzed based on the above mechanistic details. It is found that regioselectivity depends on the relative feasibility of alkene migratory insertion step. For $\mathbf{C u} / \mathbf{L}_{\mathbf{A}}$-catalyzed system, the generation of product $\mathbf{P}_{\mathbf{1}}$ is preferred mainly due to the great steric effects of TS9A that rule out the possibility to lead to $\mathbf{P}_{2}$. For $\mathbf{C u} / \mathbf{L}_{\mathbf{B}}$-catalyzed system, electronic effects become the major factors to produce the major product $\mathbf{P}_{\mathbf{2}}$. The in-depth understanding for the divergent reaction mechanisms and distinct regiochemistry could be beneficial in designing new related reactions.

\section{Acknowledgements}

This work was jointly supported by Natural Science Foundation of Shandong Province (No. ZR2014BM038), and Talent Team
Culturing Plan for Leading Disciplines of University in Shandong Province.

\section{References}

1 (a) T. Liu and S. W. Bi, Organometallics, 2016, 35, 1114; (b) R. Alam, T. Vollgraff, L. Eriksson and K. J. Szabó, J. Am. Chem. Soc., 2015, 137, 11262; (c) M. Yus, J. C. GonzálezGómez and F. Foubelo, Chem. Rev., 2013, 113, 5595; (d) I. Beletskaya and C. Moberg, Chem. Rev., 2006, 106, 2320.

2 (a) W. M. Yuan, S. Liu and S. M. Ma, Angew. Chem., Int. Ed., 2016, 55, 3140; (b) J. Rae, Y. C. Hu and D. J. Procter, Chem.Eur. J., 2014, 20, 13143; (c) J. A. Calderone and W. L. Santos, Angew. Chem., Int. Ed., 2014, 53, 4154; (d) Y. H. Xu, L. H. Wu, J. Wang and T. P. Loh, Chem. Commun., 2014, 50, 7195; (e) A. Barbero and F. J. Pulido, Acc. Chem. Res., 2004, 37, 817; (f) M. Y. Wu, F. Y. Yang and C. H. Cheng, J. Org. Chem., 1999, 64, 2471; $(g)$ E. Langkopf and D. Schinzer, Chem. Rev., 1995, 95, 1375.

3 (a) M. Uehling, R. Rucker and G. Lalic, J. Am. Chem. Soc., 2014, 136, 8799; (b) S. C. Yu and S. M. Ma, Angew. Chem., Int. Ed., 2012, 51, 3074.

4 (a) C. C. Xia, K. Wang, J. Xu, C. Shen, D. Sun, H. S. Li, G. D. Wang and P. F. Zhang, Org. Biomol. Chem., 2017, 15, 531; (b) T. Itoh, Y. Shimizu and M. Kanai, J. Am. Chem. Soc., 2016, 138, 7528; (c) M. Pirnot, Y. Wang and S. Buchwald, Angew. Chem., Int. Ed., 2016, 55, 48; (d) R. Bullock and M. Helm, Acc. Chem. Res., 2015, 48, 2017; (e) K. Semba, T. Fujihara, J. Terao and Y. Tsuji, Angew. Chem., Int. Ed., 2013, 52, 12400.

5 (a) M. Usman, Z. H. Ren, Y. Y. Wang and Z. H. Guan, RSC $A d v .$, 2016, 6, 107542; (b) Y. Y. Li, S. L. Yu, W. Y. Shen and J. X. Gao, Acc. Chem. Res., 2015, 48, 2587; (c) B. Jung and A. H. Hoveyda, J. Am. Chem. Soc., 2012, 134, 1490.

6 (a) W. Y. Li, D. F. Huang and Y. J. Lyu, Org. Biomol. Chem., 2016, 14, 10875; (b) K. Nogi, T. Fujihara, J. Terao and Y. Tsuji, Chem. Commun., 2014, 50, 13052; (c) L. Zang and Z. Hou, Chem. Sci., 2013, 4, 3395; (d) I. Omae, Coord. Chem. Rev., 2012, 256, 1384; (e) W. Wang, S. Wang, X. Ma and J. Gong, Chem. Soc. Rev., 2011, 40, 3703; $(f)$ T. Fujihara, T. Xu, K. Semba, J. Terao and Y. Tsuji, Angew. Chem., Int. Ed., 2011, 50, 523.

7 Y. Tani, T. Fujihara, J. Terao and Y. Tsuji, J. Am. Chem. Soc., 2014, 136, 17706.

8 (a) A. D. Becke, J. Chem. Phys., 1993, 98, 5648; (b) C. Lee, W. Yang and G. Parr, Phys. Rev. B: Condens. Matter Mater. Phys., 1988, 37, 785; (c) P. J. Stephens, F. J. Devlin, C. F. Chabalowski and M. J. Frisch, J. Phys. Chem., 1994, 98, 11623.

9 (a) R. Yuan and Z. Y. Lin, ACS Catal., 2014, 4, 4466; (b) H. T. Zhao, Z. Y. Lin and T. B. Marder, J. Am. Chem. Soc., 2006, 128, 15637; (c) H. T. Zhao, L. Dang, T. B. Marder and Z. Y. Lin, J. Am. Chem. Soc., 2008, 130, 5586.

10 (a) K. Fukui, J. Phys. Chem., 1970, 74, 4161; (b) K. Fukui, Acc. Chem. Res., 1981, 14, 363.

11 A. V. Marenich, C. J. Cramer and D. G. Truhlar, J. Phys. Chem. $B, 2009,113,6378$. 
12 Y. Zhao and D. G. Truhlar, Theor. Chem. Acc., 2008, 120, 215. 13 (a) J. P. Foster and F. Weinhold, J. Am. Chem. Soc., 1980, 102, 7211; (b) A. E. Reed and F. Weinhold, J. Chem. Phys., 1983, 78, 4066.

14 M. J. Frisch, G. W. Trucks, H. B. Schlegel, G. E. Scuseria, M. A. Robb, J. R. Cheeseman, G. Scalmani, V. Barone, B. Mennucci, G. A. Petersson, H. Nakatsuji, M. Caricato, X. Li, H. P. Hratchian, A. F. Izmaylov, J. Bloino, G. Zheng, J. L. Sonnenberg, M. Hada, M. Ehara, K. Toyota, R. Fukuda, J. Hasegawa, M. Ishida, T. Nakajima, Y. Honda, O. Kitao, H. Nakai, T. Vreven, J. J. A. Montgomery, J. E. Peralta, F. Ogliaro, M. Bearpark, J. J. Heyd, E. Brothers, K. N. Kudin, V. N. Staroverov, R. Kobayashi, J. Normand, K. Raghavachari, A. Rendell, J. C. Burant, S. S. Iyengar, J. Tomasi, M. Cossi, N. Rega, J. M. Millam,
M. Klene, J. E. Knox, J. B. Cross, V. Bakken, C. Adamo, J. Jaramillo, R. Gomperts, R. E. Stratmann, O. Yazyev, A. J. Austin, R. Cammi, C. Pomelli, J. W. Ochterski, R. L. Martin, K. Morokuma, V. G. Zakrzewski, G. A. Voth, P. Salvador, J. J. Dannenberg, S. Dapprich, A. D. Daniels, Ö. Farkas, J. B. Foresman, J. V. Ortiz, J. Cioslowski and D. J. Fox, Gaussian, Inc., Wallingford CT, 2009.

15 (a) B. C. Hamann and J. F. Hartwig, J. Am. Chem. Soc., 1998, 120, 3694; (b) M. Kawatsura and J. F. Hartwig, J. Am. Chem. Soc., 1999, 121, 1473.

16 M. N. Birkholz, Z. Freixa and P. W. van Leeuwen, Chem. Soc. Rev., 2009, 38, 1099.

17 Q. H. Lu, B. Wang, H. Z. Yu and Y. Fu, ACS Catal., 2015, 5, 4881. 